\title{
CONTRIBUTIONS TO TRANSFORMATION SUPERPLASTICITY OF TITANIUM FROM RIGID PARTICLES AND PRESSURIZED PORES
}

\author{
C. Schuh and D.C. Dunand \\ Department of Materials Science and Engineering, Northwestern University, Evanston, IL
}

(Received February 3, 1999)

(Accepted February 12, 1999)

\begin{abstract}
$\underline{\text { Introduction }}$
Polymorphic materials which are subjected to an external stress while their temperature is repeatedly cycled about their phase transformation range experience, on average, Newtonian flow, which is driven by the biasing of internal transformation mismatch stresses by the external stress (1). This phenomenon, termed transformation superplasticity, is well documented for metals (as reviewed in Ref. (2)) and has recently been demonstrated for metal-matrix composites (MMCs) with a polymorphic matrix and a discontinuous, non-transforming reinforcement phase (3-5). The first report of transformation superplasticity of a MMC was that published by Dunand and Bedell (D\&B) (3), who examined commercialpurity titanium (CP-Ti) reinforced with 10 vol. \% particulate TiC. Furthermore, as compared to unreinforced $\mathrm{CP}-\mathrm{Ti}$ specimens at the same stress, they observed an enhancement of the superplastic strain increment produced upon each thermal cycle for the composite. They attributed this effect to increased mismatch produced during the phase transformation of the matrix due to the presence of the rigid, non-transforming reinforcement phase.

In our current investigation of transformation superplasticity of materials with the same nominal composition as those used in the original study of D\&B (3), we have become aware of a microstructural feature of the experimental material which affects the superplastic strain increments, and which results in differences between the data of the two studies. In the present paper, we report the details of this effect and critically re-examine the original conclusions of D\&B (3).
\end{abstract}

\section{$\underline{\text { Experimental }}$}

As for the D\&B investigation (3), our experimental material was unalloyed CP titanium with and without 10 vol. \% TiC reinforcement, manufactured (in a different batch from those of D\&B) at Dynamet Technology (Burlington, MA) by their CHIP process (6), which involves blending of powders, cold isostatic pressing, vacuum sintering, and hot isostatic pressing in argon without encapsulation. One small piece of the Ti/10\% TiC material $(12 \times 4 \times 2 \mathrm{~mm})$ was annealed in argon at $1010^{\circ}$ $\mathrm{C}$ in two stages of $45 \mathrm{~min}$. duration each before densiometric investigation. Tensile specimens of each material with $20 \mathrm{~mm}$ gauge length and $5 \mathrm{~mm}$ gauge diameter were tested under high-purity argon in a tensile creep apparatus described in detail in Ref. (7), and with procedures and analysis described in Ref. (8). Thermal cycle profiles, selected to emulate those used in the original work of D\&B (3), are 


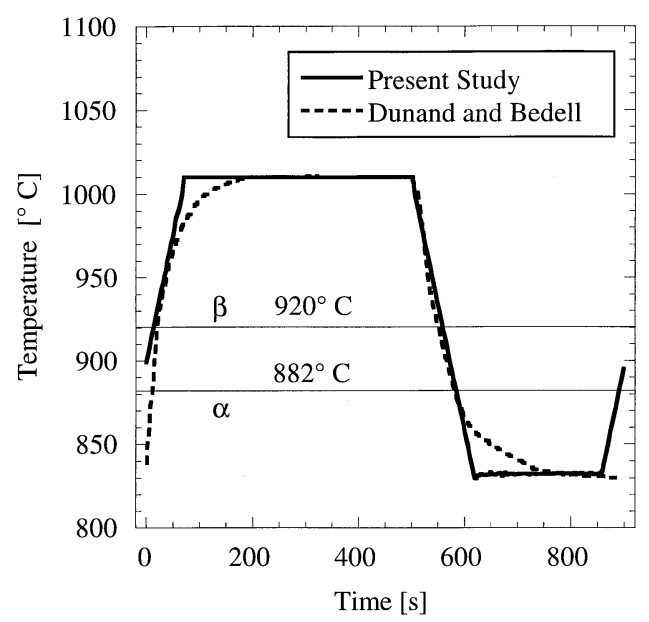

Figure 1. Experimental thermal cycle profile used in the present study and in the original work of Dunand and Bedell (3). The allotropic temperature of pure (i.e., oxygen free) titanium is shown at $882^{\circ} \mathrm{C}(15)$, and that of carbon-containing titanium at $920^{\circ} \mathrm{C}$ (15).

shown in Fig. 1 for the composite material. The thermal cycles used with CP-Ti were similar to those in Fig. 1, but with an upper temperature of $1030^{\circ} \mathrm{C}$ instead of $1010^{\circ} \mathrm{C}$. Prior to isothermal creep and thermal cycling experiments, each specimen was annealed at the upper cycle temperature for 75 minutes.

Several deformed specimens used in the work of D\&B (3) were examined to elicit any microstructural difference from the material of the present study. Density was measured by the Archimedes method in distilled water and metallographic preparation consisted of grinding on abrasive SiC paper of 240-600 grit, followed by polishing with suspensions of diamond ( 6 and $1 \mu \mathrm{m})$ and alumina $(0.05$ $\mu \mathrm{m})$.

\section{Results and Discussion}

\section{Effect of Pressurized Pores on Superplastic Strain Increments}

Our as-received $\mathrm{Ti} / 10 \% \mathrm{TiC}$ specimens exhibited about $95.5 \%$ theoretical density, similar to that reported by D\&B (96\%) (3). Furthermore, optical observations revealed a microstructure similar to that shown in their article, with much of the porosity contained in the $\mathrm{TiC}$ reinforcement particles rather than the matrix (Fig. 2b in Ref. (3)). Upon annealing at $1010^{\circ} \mathrm{C}$ for $45 \mathrm{~min}$. the relative density of our unstressed specimens decreased to $94.0 \%$. An additional $45 \mathrm{~min}$. at $1010^{\circ} \mathrm{C}$ did not result in any further density change.

The strain increments $\Delta \epsilon_{\text {tot }}$ measured for both materials after a complete thermal cycle are shown in Fig. 2. Presented for comparison are the results of D\&B (3) for Ti/10\% TiC and CP-Ti. All the materials exhibited a linear relationship between $\Delta \epsilon_{\text {tot }}$ and $\sigma$, typical of transformation superplasticity $(1,2)$. Although the respective materials compositions, thermal cycle characteristics, and stress ranges are all similar, the superplastic strain increments shown in Fig. 2 are much larger in the work of D\&B (3).

Furthermore, the optical micrographs of Fig. 3 reveal a significant microstructural difference between the two Ti/10\% TiC materials after superplastic deformation. A composite specimen from the present study subjected to isothermal creep and thermal cycling at various tensile stresses and deformed 


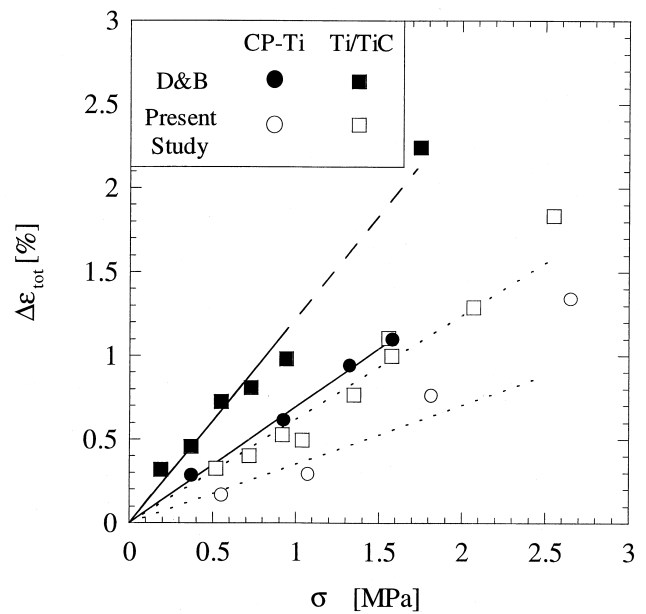

Figure 2. Total strain increment $\Delta \epsilon_{\text {tot }}$ produced after a complete thermal cycle with applied uniaxial stress $\sigma$ for CP-Ti and $\mathrm{Ti} / 10 \% \mathrm{TiC}$ composite from the present investigation as well as from Ref. (3).

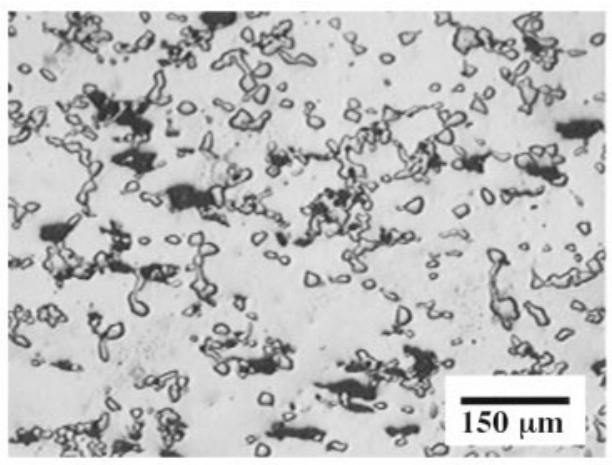

(a)

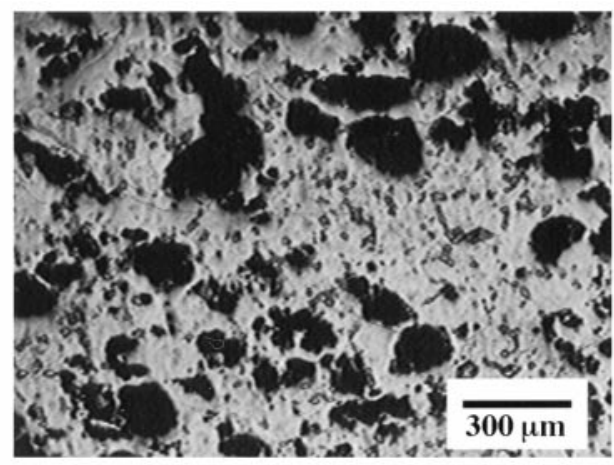

(b)

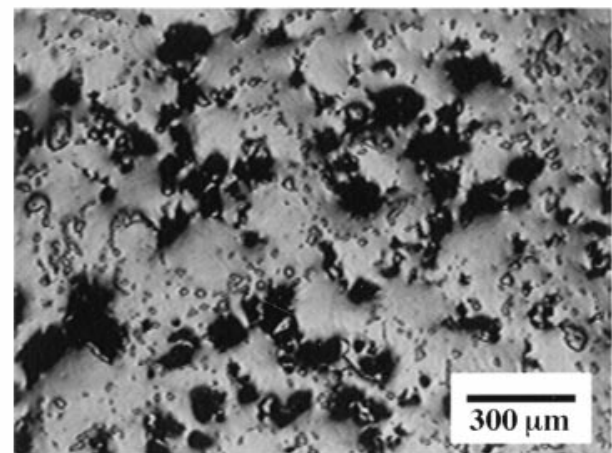

(c)

Figure 3. Optical micrographs of superplastically deformed $\mathrm{Ti} / 10 \% \mathrm{TiC}$ composites. (a) present investigation, gauge, $87 \%$ strain, (b) from the investigation of D\&B (3), gauge, $80 \%$ strain, $82 \%$ density, and (c) from D\&B (3), head, $80 \%$ strain, $82 \%$ density. 


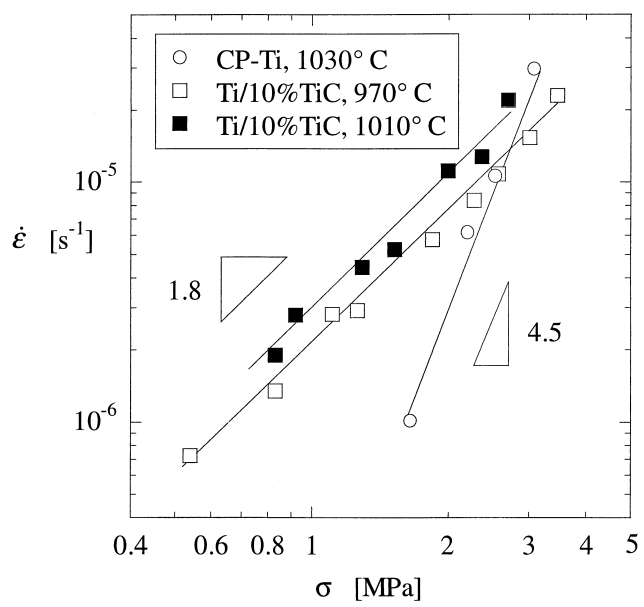

Figure 4. Isothermal minimum creep rate $\dot{\epsilon}$ vs. applied tensile stress $\sigma$ for $\mathrm{CP}-\mathrm{Ti}$ at $1030^{\circ} \mathrm{C}$ and for $\mathrm{Ti} / 10 \% \mathrm{TiC}$ at $970{ }^{\circ} \mathrm{C}$ and $1010^{\circ} \mathrm{C}$.

without failure to $87 \%$ engineering strain is shown in Fig. 3a. This micrograph shows cavities initially present in the composite before deformation, and possibly some produced by cavitation during deformation. Larger ellipsoidal pores are also present in small numbers. Figs. $3 \mathrm{~b}$ and $3 \mathrm{c}$ show the microstructure of a tensile specimen used in the original work of D\&B (3) from the gauge and head sections of the specimen, respectively. Although the exact history of this specimen is complex, it was subjected to isothermal creep and thermal-cycling tensile experiments to a strain of about $80 \%$ without failure. The porosity in both the gauge and head sections is considerable, and each pore is very large $(\sim 100-200 \mu \mathrm{m})$. The relative density of the heads and gauge were determined as $86 \%$ and $82 \%$, respectively. The materials of D\&B (3) (Figs. 3b and 3c) clearly accumulated significantly more and generally larger porosity than the materials of the present study (Fig. 3a) when subjected to superplasticity experiments, despite similar initial densities and test conditions. Moreover, the uniform presence of very large cavities in the sample heads, where the applied stress is very low, indicates that the cavities are not produced by tensile deformation alone. The material of the present study exhibited some large pores similar to those in the materials of D\&B (3), but with much lower frequency and average size than in those materials.

A likely explanation for the presence of these large pores is that the materials of the present study as well as those of D\&B (3) contained small pockets of entrapped gas, which subsequently expanded when the specimens were tested at elevated temperatures. If some open porosity is present following vacuum sintering, closed argon-containing porosity can form during the early stages of containerless hot isostatic pressing. These pores will then shrink during the later stage of compaction until their internal pressure is equal to the isostatic processing pressure (103 MPa for CP-Ti and $172 \mathrm{MPa}$ for Ti/TiC (3)). This mechanism has been documented for $\mathrm{CP}-\mathrm{Ti}$ and $\mathrm{Ti}-6 \mathrm{Al}-4 \mathrm{~V}$, where argon gas was intentionally entrapped and subsequently expanded by creep of the surrounding matrix $(9,10)$ or by transformation superplasticity (10) to create high-porosity metallic foams. Indeed, the micrographs in Figs. 3b and 3c are qualitatively similar to micrographs of such foams in Ref. (10). The presence of gas-filled porosity also allows for reinterpretation of the thermal ratcheting data of D\&B (Fig. 4 of Ref. (3)) as well as the large unrecovered strain of about $2.5 \%$ (11) observed in one of their composite specimens during a dilatometric temperature excursion to $1000^{\circ} \mathrm{C}(3)$.

Pressurized cavities can affect the superplastic strain increment produced after a complete thermal cycle in several ways: 
(i) As with creep cavitation, internal pores reduce the load-bearing area of the specimen and act as stress concentration sites, increasing the deformation rate. However, for materials deforming under Newtonian conditions the effect of stress concentration near such pores is small.

(ii) Pressurized pores can expand both by creep and transformation superplasticity of the surrounding matrix, thus contributing to overall sample elongation (10). The development of large pores in, and resulting swelling of, the (nominally stress-free) heads of D\&B's (3) specimens (Fig. 3c) are evidence to the operation of this mechanism.

(iii) Matrix flow induced by internal gas pressure can be biased by the external uniaxial tensile stress. This is similar to the mechanism of transformation superplasticity, where the internal stresses created by the phase transformation are biased in the tensile direction and result in superplastic strain increments. In the present case, both the transformation mismatch stresses and pore pressure are biased by the external stress, increasing the strain increment for a given cycle.

All three of the above effects of entrapped gas are expected to increase the macroscopic strain increment developed in the specimen over a complete thermal cycle.

Based on the density change of the unstressed specimen annealed for $45 \mathrm{~min}$. and $90 \mathrm{~min}$. at $1010^{\circ} \mathrm{C}$ ( $94.0 \%$ theoretical after both stages), we expect that the small number of pressurized pores in our material were fully expanded (to ambient pressure) in less than 45 minutes at that temperature. Therefore, to minimize the above effects of entrapped gas on the superplastic strain increments, our tensile specimens were annealed at $1010^{\circ} \mathrm{C}(\mathrm{Ti} / 10 \% \mathrm{TiC})$ or $1030^{\circ} \mathrm{C}(\mathrm{CP}-\mathrm{Ti})$ for $75 \mathrm{~min}$ prior to mechanical testing. Without gas pressure in the pores, only effect (i) above can potentially affect the superplastic strain increments of our material (Fig. 2), although for superplastic deformation this effect can be considered small. The prompt start of the superplasticity experiments of D\&B (3) did not allow sufficient time to fully expand the pores prior to superplastic deformation, resulting in all three of the above contributions to deformation during thermal cycling.

We conclude that the large number of macroscopic pores in the materials of D\&B (3) combined with their very large strain increment data (Fig. 2) suggest that expansion of gas-containing pores contributed significantly to the deformation of their materials during superplasticity experiments. Because we have used materials with considerably less entrapped gas than those of D\&B (3) and have annealed our materials to minimize the effects of pressurized pores prior to superplasticity experiments, we believe that our data in Fig. 2 are intrinsic to the respective materials, and contain no additional contribution due to entrapped gas.

\section{$\underline{\text { Effect of Reinforcement on Superplastic Strain Increments }}$}

D\&B (3) reported significant increases in the superplastic strain increments of unalloyed titanium due to the presence of reinforcing $\mathrm{TiC}$ particles. This enhancement was attributed to the additional mismatch caused by the transformation of the matrix against rigid particles. Adapting to transformation mismatch superplasticity a model of Sato and Kuribayashi (12) developed for thermal expansion mismatch superplasticity, D\&B (3) predicted the additional strain increment $\Delta \bar{\epsilon}$ produced during a complete thermal cycle due to the presence of the reinforcement:

$$
\Delta \bar{\epsilon}=\int_{\Delta t} \frac{4 n(n+4)}{2^{1 / n} \cdot 5} \cdot \frac{\left(1-f^{1 / n}\right)}{(1-f)^{2}} \cdot\left[\frac{f}{\Delta t} \cdot\left(\left|\frac{1}{3} \cdot \frac{\Delta V}{V}\right|-\left|\Delta \alpha \cdot \Delta T^{\prime}\right|\right)\right]^{1-1 / n}(\dot{\epsilon}(\sigma, T))^{1 / n} \cdot d t
$$

where $n$ is the creep stress exponent of the weaker matrix phase $(\beta$-Ti), $f$ is the volume fraction of reinforcement, $\Delta \mathrm{t}$ is the duration of the heating or cooling ramp through the temperature interval $\Delta \mathrm{T}$ ' 


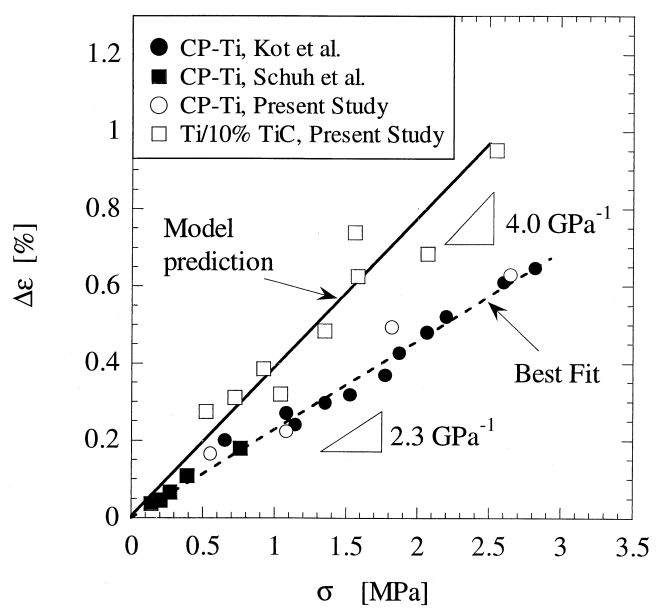

Figure 5. Strain increment $\Delta \epsilon$ vs. applied stress $\sigma$ for CP-Ti and Ti/10\% TiC after subtraction of the creep-strain contribution to deformation. Additional data for CP-Ti are from the work of Schuh et al. (13) and Kot et al. (19). The enhancement due to the presence of reinforcement predicted by equation (1) is also shown.

between the upper cycling temperature and the phase transus, $\Delta \mathrm{V} / \mathrm{V}$ is the volume mismatch between the two allotropic matrix phases, $\Delta \alpha$ is the difference between the linear thermal expansion coefficients of the weaker matrix phase and the reinforcement, and $\dot{\epsilon}(\sigma, T)$ is the steady-state creep law describing the deformation of the weaker matrix phase.

Since, as discussed in the previous section, the data of D\&B (3) contain two effects, it is necessary to re-examine their conclusion regarding the enhancement of superplastic strain increments for MMCs. In the following, we use data from the present study to assess the effect of reinforcement addition on the superplastic strain increments produced during transformation superplasticity experiments.

Comparison of superplastic strain increment data requires that the transformation contribution to deformation be isolated from other strain contributions. In the present case, care has been taken to eliminate the contributions from entrapped gas, so only the contribution of steady-state creep outside the temperature range of the transformation needs to be subtracted. This is accomplished by numerical integration of each material's creep law over the thermal cycle profile as discussed in Ref. (3). This calculation requires information on the creep behavior of the experimental materials in the titanium $\beta$-field. To this end, a limited amount of creep data was collected for both experimental materials at stresses between 0.5 and $3.5 \mathrm{MPa}$ as shown in Fig. 4. Both materials exhibit a typical power-law type relationship with stress exponents of about 4.5 for $\mathrm{CP}-\mathrm{Ti}$ and 1.8 for the composite. The low stress exponent and rapid creep of the composite at lower temperature and stresses than $\mathrm{CP}-\mathrm{Ti}$ is related to the much smaller grain size of the composite, as discussed in Refs. $(3,13)$. We note that the creep data of $\mathrm{Ti} / 10 \% \mathrm{TiC}$ in Fig. 4 are in good agreement with the data of D\&B (3), and those of CP-Ti are reasonably close to those of Refs. (3) and (14).

For determination of the creep strain accumulated on each thermal cycle, we use the creep data from Fig. 4 extrapolated to different temperatures by an Arrhenius relationship with $\mathrm{Q}=153 \mathrm{~kJ} / \mathrm{mol}$, the activation energy for self-diffusion of $\beta$-Ti from Ref. (14). The low-temperature $\alpha$-phase is assumed non-creeping for the purposes of the calculation, and the $\alpha / \beta$ transus is taken as $882^{\circ}$ for CP-Ti (15) and $920^{\circ} \mathrm{C}$ for $\mathrm{Ti} / 10 \% \mathrm{TiC}$ from the Ti-C phase diagram (15). Subtraction of the integrated creep strain accumulated during a complete thermal cycle results in the strain increment due solely to transformation superplasticity, $\Delta \epsilon$, as presented in Fig. 5. 
Of the several studies of transformation superplasticity of CP-Ti in the literature (13,16-19), those of Kot et al. (19) and Schuh et al. (13) are most suited for comparison with the present experimental data. Kot et al. (19) employed induction heating to achieve extremely rapid thermal cycles ( $30 \mathrm{sec}$.), essentially eliminating isothermal creep outside the transformation range. The thermal cycles of Schuh et al. (13) were somewhat longer (4 min.), but at very low applied stresses where creep outside the transformation range is negligible. This was verified by performing the numerical creep-strain calculation as done above: below about $1 \mathrm{MPa}$, creep outside the transformation range is negligible for their cycles. Appropriate data from these two studies are plotted in Fig. 5, and are shown to be consistent with one another and with the data from the present study.

Comparison of the $\mathrm{Ti} / 10 \% \mathrm{TiC}$ and $\mathrm{CP}-\mathrm{Ti}$ strain increment data in Fig. 5 reveal a significant enhancement caused by the addition of $\mathrm{TiC}$ reinforcement, qualitatively similar to the original result of $\mathrm{D} \& \mathrm{~B}$ (3). Taking the same materials data as $\mathrm{D} \& \mathrm{~B}$ (3), i.e., $\mathrm{f}=0.10, \Delta \mathrm{V} / \mathrm{V}=0.48 \%, \Delta \alpha=2.8 \cdot 10^{-6}$ $\mathrm{K}^{-1}, \mathrm{n}=4.3$, the creep power-law equation of $\beta$-Ti for $\dot{\epsilon}(\sigma, T)$ from Ref. (14), and numerically integrating Eq. (1) over the appropriate segment of the thermal cycle shown in Fig. $1(\Delta \mathrm{t} \approx 55 \mathrm{~s}, \Delta \mathrm{T}$ ' $\approx 90 \mathrm{~K})$ predicts an enhancement $\Delta \epsilon / \sigma=1.7 \mathrm{GPa}^{-1}$ due to the presence of $10 \% \mathrm{TiC}$ reinforcement. The result of adding this enhancement to the superplastic strain increment expected for the matrix alone (determined by best-fit from Fig. 5 as $\Delta \epsilon / \sigma=2.3 \mathrm{GPa}^{-1}$ ) is also shown in Fig. 5. The agreement with the experimental data is quite good, especially since no adjustable parameters were used, but it must be noted that there are many assumptions in the creep-strain calculations and in the assignment of variables in Eq. (1), as discussed by D\&B (3). Furthermore, although special care was taken to minimize the effects of entrapped gas, the large remnant pores present during deformation may somewhat increase the superplastic strain increment. Finally, microstructural evolution during the thermal cycling and deformation of $\mathrm{Ti} / 10 \% \mathrm{TiC}$ may affect the creep and superplastic behavior of the composites, as discussed in Ref. (13).

\section{Conclusions}

Transformation superplasticity of unalloyed commercial purity titanium and $\mathrm{Ti} / 10 \% \mathrm{TiC}$ composites has been reexamined and compared with an original study by Dunand and Bedell (3) on materials with the same nominal composition and microstructure. Comparison of superplastic strain increment data and post-deformation microstructures of the two investigations reveals that the materials used in the original work most probably contained pockets of gas entrapped during processing which expanded during the high-temperature tests, leading to an additional contribution to the measured strain increments during thermal cycling. The materials used in the present investigation contained a much smaller amount of entrapped gas, and a pre-deformation anneal assured that no gas pressure remained to affect the superplasticity experiments. The main qualitative conclusion of Dunand and Bedell's work (3) is confirmed; the addition of discontinuous, rigid, non-transforming particles to titanium appears to enhance the superplastic strain accumulated during a complete thermal cycle about the phase transformation temperature of the matrix. Furthermore, the model originally proposed by Dunand and Bedell (3) predicts the magnitude of this enhancement with accuracy.

\section{Acknowledgments}

This research was funded by National Science Foundation (through a subcontract from Dynamet Technology under SBIR grant \#9760593), the U.S. Army Research Office (under grant DAAH00495-1-0629, monitored by Dr. K. Logan) and the U.S. Department of Defense (through a National 
Defense Science and Engineering Graduate Fellowship for C.S.). Useful discussions with W. Zimmer from Dynamet Technology are also acknowledged.

\section{References}

1. T. G. Nieh, J. Wadsworth, and O. D. Sherby, Superplasticity in Metals and Ceramics, Cambridge University Press, Cambridge, UK (1997).

2. D. C. Dunand, in International Conference on Thermomechanical Processing of Steels and Other Materials, ed. T. Chandra and T. Sakai, pp. 1821-1830, TMS, Warrendale, PA (1997).

3. D. C. Dunand and C. M. Bedell, Acta Mater. 44, 1063 (1996).

4. D. C. Dunand and S. Myojin, Mater. Sci. Eng. 230A, 25 (1997).

5. P. Zwigl and D. C. Dunand, Metall. Mater. Trans. 29A, 565 (1998).

6. S. Abkowitz, P. F. Weihrauch, and S. M. Abkowitz, Ind. Heating. 12, 32 (1993).

7. P. Zwigl and D. C. Dunand, Metall. Mater. Trans. 29A, 2571 (1998).

8. C. Schuh and D. C. Dunand, Acta Mater. 46, 5663 (1998).

9. M. W. Kearns, P. A. Blenkinsop, A. C. Barber, and T. W. Farthing, Int. J. Powder Metall. 24, 59 (1988).

10. D. C. Dunand and J. Teisen, in Porous and Cellular Materials for Structural Applications, ed. D. S. Schwartz et al., vol. 521, pp. 231-236, MRS, Pittsburgh (1998).

11. C. M. Bedell, M.S. Thesis, Massachusetts Institute of Technology (1993).

12. E. Sato and K. Kuribayashi, Acta Metall. Mater. 41, 1759 (1993).

13. C. Schuh, W. Zimmer, and D. C. Dunand, in Creep Behavior of Advanced Materials for the 21st Century, ed. R. S. Mishra and A. K. Mukherjee, TMS, Warrendale, in press (1999).

14. H. J. Frost and M. F. Ashby, Deformation-Mechanism Maps: The Plasticity and Creep of Metals and Ceramics, p. 166, Pergamon Press, Oxford, UK (1982).

15. ASM Handbook: Alloy Phase Diagrams, vol. 3, ASM, Metals Park, OH (1992).

16. G. W. Greenwood and R. H. Johnson, Proc. Roy. Soc. Lond. 283A, 403 (1965).

17. C. Chaix and A. Lasalmonie, Res Mech. 2, 241 (1981).

18. N. Furushiro, H. Kuramoto, Y. Takayama, and S. Hori, Trans. ISIJ. 27, 725 (1987).

19. R. Kot, G. Krause, and V. Weiss, in The Science, Technology and Applications of Titanium, ed. R. I. Jaffe and N. E. Promisel, pp. 597-605, Pergamon, Oxford, UK (1970). 